\title{
Microstructure and Mechanical Properties of Intercritical Heat-affected Zone of X80 Pipeline Steel in Simulated In-Service Welding
}

\author{
Xin-Jie Di ${ }^{1,2} \cdot$ Lin Cai ${ }^{1,2} \cdot$ Xi-Xue Xing ${ }^{1,2} \cdot$ Cui-Xin Chen ${ }^{3}$ Zhen-Kui Xue ${ }^{4}$
}

Received: 2 September 2014/Revised: 31 December 2014/Published online: 5 May 2015

(C) The Chinese Society for Metals and Springer-Verlag Berlin Heidelberg 2015

\begin{abstract}
The intercritical heat-affected zone (ICHAZ) of X80 pipeline steel was simulated by using the Gleeble-3500 thermal/mechanical simulator according to the thermal cycle of in-service welding. The microstructures of ICHAZ with different cooling rates were examined, and the hardness, the toughness and corresponding fractography were investigated. Results show that untransformed bainite and ferrite as well as retransformed fine bainite and martensite-austenite (M-A) constituents constitute the microstructure of ICHAZ. The two different morphologies of M-A constituents are stringer and block. Second phase particles which mainly composed of $\mathrm{Ti}, \mathrm{Nb}, \mathrm{C}, \mathrm{Fe}$ and $\mathrm{Cu}$ coarsened in ICHAZ. Compared with normal welding condition, the toughness of ICHAZ is poor when the cooling time is short under in-service welding condition because of the large area fraction and size of $\mathrm{M}-\mathrm{A}$ constituents that connect into chains and distribute at the grain boundaries. The Vickers hardness of ICHAZ that decreases with the increase in the cooling time is independent with the area fraction of M-A constituents.
\end{abstract}

KEY WORDS: X80 pipeline steel; In-service welding; Heat-affected zone; Microstructure; Toughness

\section{Introduction}

For its excellent balance between the strength and toughness properties, low-carbon microalloyed high-performance pipeline steel that is mainly composed of bainite has been widely used in the oil and gas pipeline construction [1].

Available online at http://link.springer.com/journal/40195

Xin-Jie Di

dixinjie@tju.edu.cn

1 School of Materials Science and Engineering, Tianjin University, 25C-805, No. 92 Weijin Road, Tianjin 300072, China

2 Tianjin Key Laboratory of Advanced Joining Technology, Tianjin 300072, China

3 School of Materials Science and Engineering, Hebei University of Technology, Tianjin 300401, China

4 China Petrolum Pipeline Bureau, Langfang 065000, China
However, the good strength and toughness can be deteriorated by the thermal cycles after welding, producing local brittle zones in heat-affected zone (HAZ) [2]. Recently researches showed that the coarse grain HAZ (CGHAZ) adjacent to the fusion line always has the lowest toughness in single pass welding because of the formation of some unfavorable microstructures such as large-size prior-austenite grains and $\mathrm{M}-\mathrm{A}$ constituents [3, 4]. The decrease in toughness arising from the asymmetrical microstructure was also reported in ICHAZ where the transformation of ferrite to austenite occurs particularly [5].

In-service welding technology is a high-efficiency and low-cost way to repair the broken pipelines [6]. Many researchers have done a lot of work to study in-service welding technology, and these studies mainly focused on how to prevent the burn-through, hydrogen-induced cracks and other defects during in-service welding process [7-11]. Because during in-service welding the flowing oil and gas create a large amount of heat loss through the pipeline wall, the cooling rate is much faster than normal welding 
process. The accelerated cooling of the welding joint was reported to affect the microstructure significantly and also may increase hardness, decrease toughness and promote local brittle zones phenomenon in CGHAZ [12]. However, for ICHAZ which may also have low toughness, there are little systematic and in-depth studies on its microstructure and mechanical properties.

In this research, the thermal simulation technology was used to study the microstructure, performance and fracture characteristics of ICHAZ of X80 pipeline steel under the condition of in-service welding with different cooling rates and the mechanism of the toughness deterioration was revealed.

\section{Experimental}

Thermal simulation samples were machined from API 5L X80 pipeline steel with a diameter of $1219 \mathrm{~mm}$ and thickness of $22.5 \mathrm{~mm}$. The chemical composition of X80 pipeline steel is composed of (wt\%) $0.06 \mathrm{C}, 0.19 \mathrm{Si}, 1.63 \mathrm{Mn}$, $0.16 \mathrm{Cr}, 0.01 \mathrm{Mo}, 0.03 \mathrm{Ni}, 0.03 \mathrm{Cu}, 0.04 \mathrm{Nb}, 0.02 \mathrm{Ti}, 0.009$ $\mathrm{P}, 0.004 \mathrm{~S}$, and Fe balanced. As shown in Fig. 1, the microstructure of the received X80 pipeline steel mainly consists of the granular bainite (GB) and small amount of quasi-polygonal ferrite (QPF).

The Gleeble-3500 thermal/mechanical simulation testing machine was used to conduct the thermal simulation, and the thermal cycle curves are schematically shown in Fig. 2. The specific process involved heating the samples to the peak temperature of $800{ }^{\circ} \mathrm{C}$ with the same heating rate of approximately to $100{ }^{\circ} \mathrm{C} / \mathrm{s}$ and holding at the peak temperature for $1.0 \mathrm{~s}$ and then cooling to $300{ }^{\circ} \mathrm{C}$ with different cooling rates. Based on our previous work [13], the cooling time which is from the peak temperature $800-500{ }^{\circ} \mathrm{C}\left(t_{8 / 5}\right)$ was controlled at 2.5, 4.0 and 5.5 $\mathrm{s}$ to compare the effect of heat input on the microstructure and mechanical properties of ICHAZ under inservice condition. A cooling time of $15 \mathrm{~s}$ was carried out to

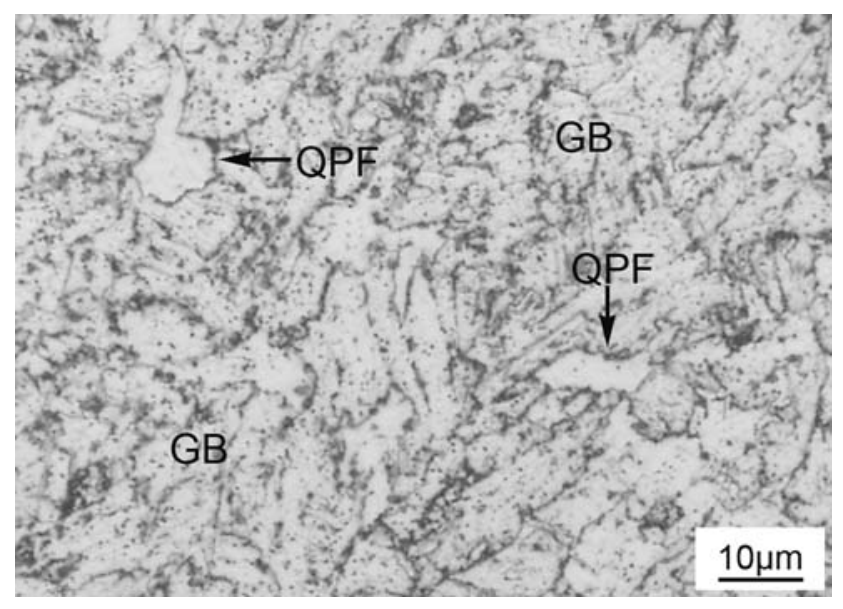

Fig. 1 Microstructure of X80 steel

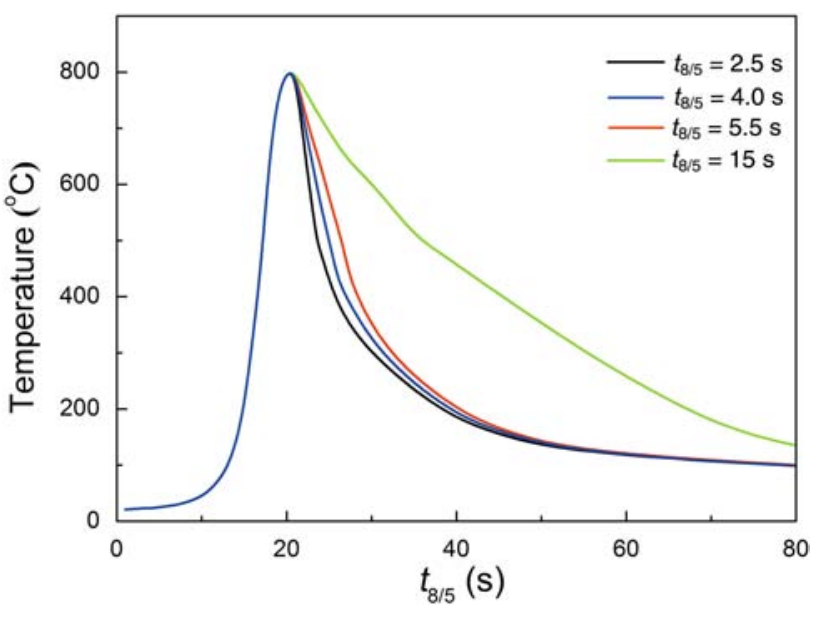

Fig. 2 Thermal cycle curves of ICHAZ used in research

represent the normal welding condition for comparison. Because of the high cooling rate, when $t_{8 / 5}$ is $2.5 \mathrm{~s}$ and $4.0 \mathrm{~s}$, the samples were machined into cylinder with the dimensions $10 \mathrm{~mm} \times 6 \mathrm{~mm} \times 80 \mathrm{~mm}$ (outer diameter $\times$ inner diameter $\times$ length) in order to obtain a uniform temperature inside and outside of the samples in the process of thermal simulation. And when $t_{8 / 5}$ is $5.5 \mathrm{~s}$ and $15 \mathrm{~s}$, the samples were machined into the dimensions $10.5 \mathrm{~mm} \times 10.5 \mathrm{~mm} \times$ $80 \mathrm{~mm}$ (length $\times$ width $\times$ height).

After thermal simulation, three samples simulated with $t_{8 / 5}$ of $5.5 \mathrm{~s}$ and $15 \mathrm{~s}$ were taken out and machined into standard samples for Charpy impact test according to the GB/T229-1994. The value of absorbed energy was measured at the temperature of $-20{ }^{\circ} \mathrm{C}$ on a JB-500 impact test machine. Then, JEOL JSM-6360LV scanning electron microscope (SEM) was used to observe the microscopic characteristics of fracture. In order to characterize the microstructure of the ICHAZ, the samples were prepared by grinding and polishing and then etched for revealing the microstructure. The microstructures were observed with OLYMPUS GX51 optical microscope (OM), JEOL JSM6360LV SEM and PHILIPS CM200 transmission electron microscope (TEM). Thin-foil samples for TEM were prepared to observe the fine microstructure of ICHAZ. The image processing software Image Pro was used to estimate the area fraction of $\mathrm{M}-\mathrm{A}$ constituents and reverted austenite. 432 SVD digital Vickers hardness tester was used to measure the Vickers hardness of the samples under a $98 \mathrm{~N}$ load.

\section{Results and Discussion}

\subsection{Microstructure and M-A Constituent}

The optical metallography of ICHAZ is shown in Fig. 3. According to the empirical formula of Andrew [14], the $A_{\mathrm{c} 1}$ 
and $A_{\mathrm{c} 3}$ temperatures of the experimental steel are 713 and $869{ }^{\circ} \mathrm{C}$, respectively. Therefore, only part of the original ferrite and bainite was austenitized during the process of thermal simulation because the simulated peak temperature was $800{ }^{\circ} \mathrm{C}$. As a result, the microstructure of ICHAZ consisted of the untransformed bainite, the untransformed ferrite and the island structures which transformed from the austenite during the cooling process. The untransformed bainite and the ferrite grew constantly during the process of heating and cooling, causing the coarsening of the bainite and the ferrite in ICHAZ.

During the process of heating, austenite nucleated and grew at the grain boundaries primarily due to the carbon absorption, the easy diffusion of alloying atoms and the irregular arrangement of atoms at the grain boundary [15]. Then the austenite converted into the bainite and a small amount of ferrite due to the high cooling rate and low carbon content during the subsequent cooling process. There were also M-A constituents distributed at the boundaries of bainite and ferrite caused by carbon concentrate during the phase transformation. To reveal M-A constituents clearly, the samples were etched by Lepera agent and shown in Fig. 4. When $t_{8 / 5}$ is $2.5,4.0$ and $5.5 \mathrm{~s}$, the size of $\mathrm{M}-\mathrm{A}$ constituents was large and the M-A constituents connected as chains shape at the grain boundaries (Figs. 3, 4). These hard and brittle M-A constituents divided the grains and generated stress concentration under applied stress. When the concentrated stress exceeds the critical stress, the micro-cracks will form at the $\mathrm{M}-\mathrm{A}$ constituents and its surroundings, leading to a significant deterioration of toughness [2]. When $t_{8 / 5}$ is $15 \mathrm{~s}$, the size of bainite and ferrite was larger and majority of supercooled austenite has already decomposed into ferrite and bainite before the martensitic transformation due to the relatively low cooling rate. Besides, owing to the long time at high temperature, auto-tempering decomposing occurred on part of martensite [16]. Hence, the area fraction and size of M-A constituents reduced sharply. Furthermore, they no longer connected into chains and distributed dispersedly (Figs. 3d, 4d).

The SEM and TEM investigations were performed for the further study of microstructural feature of ICHAZ
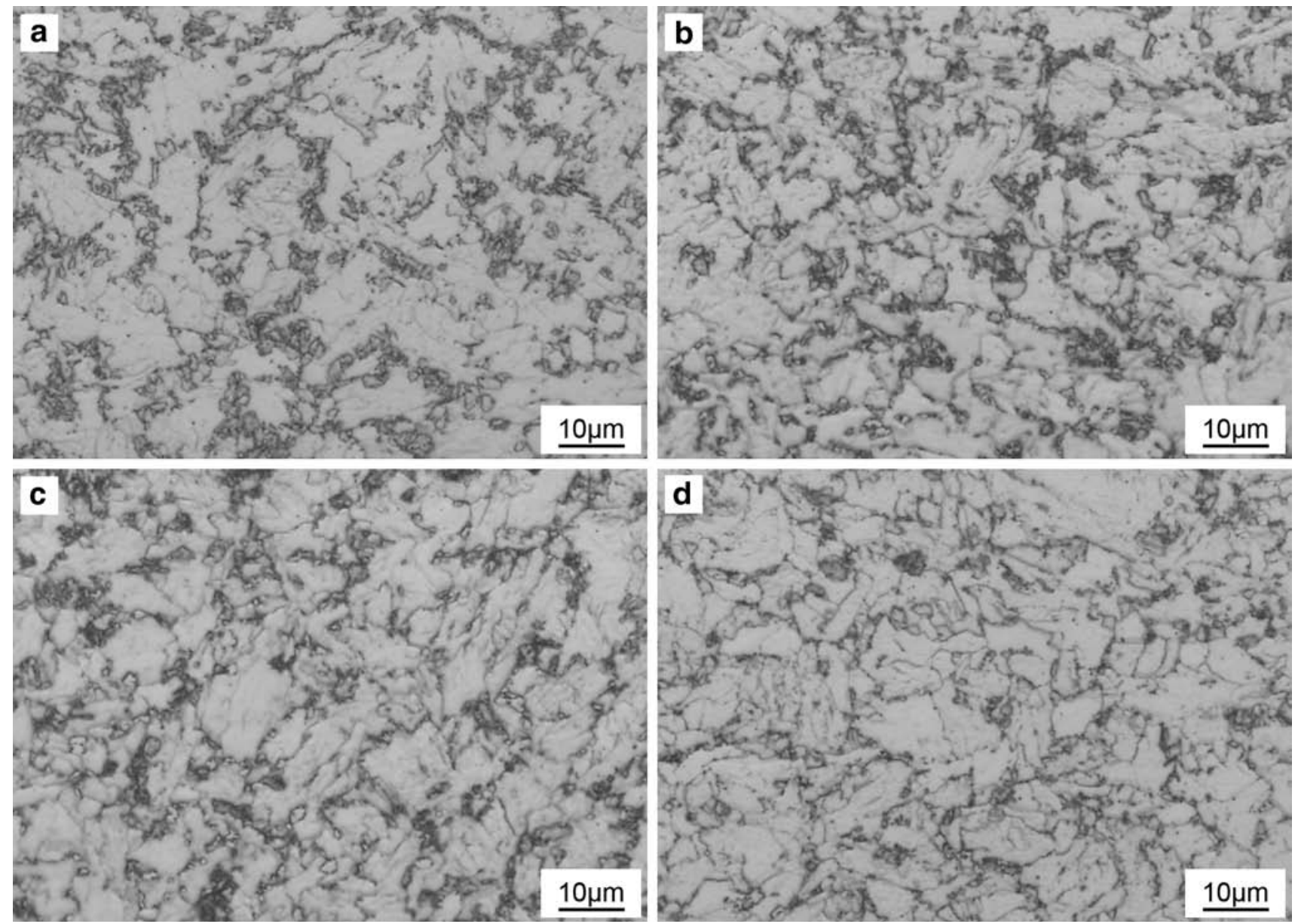

Fig. 3 Metallographs of ICHAZ samples: a $t_{8 / 5}=2.5 \mathrm{~s} ; \mathbf{b} t_{8 / 5}=4 \mathrm{~s} ; \mathbf{c} t_{8 / 5}=5.5 \mathrm{~s} ; \mathbf{d} t_{8 / 5}=15 \mathrm{~s}$ 

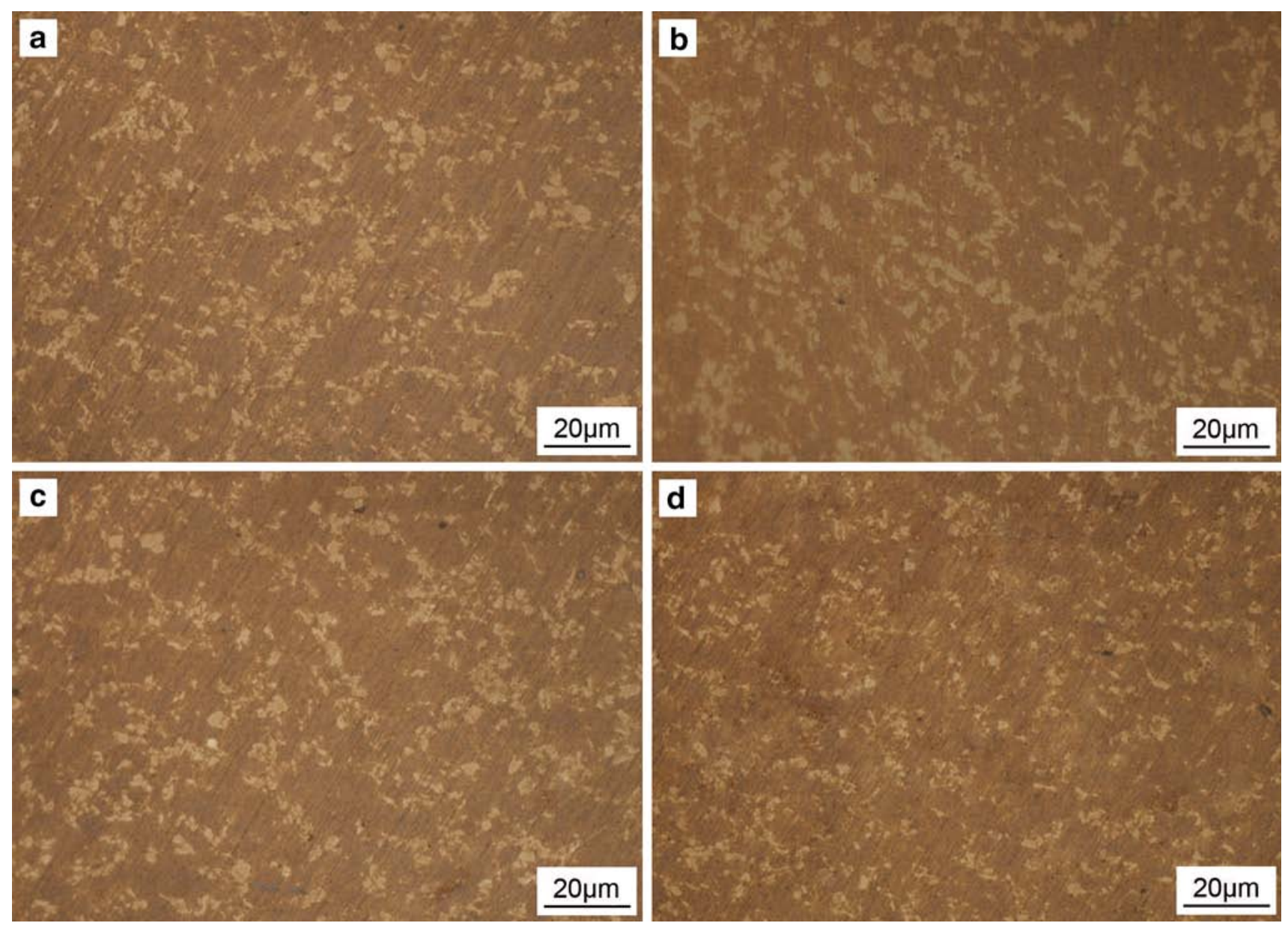

Fig. $4 \mathrm{M}-\mathrm{A}$ constituents revealed by Lepera agent: a $t_{8 / 5}=2.5 \mathrm{~s} ; \mathbf{b} t_{8 / 5}=4 \mathrm{~s} ; \mathbf{c} t_{8 / 5}=5.5 \mathrm{~s} ; \mathbf{d} t_{8 / 5}=15 \mathrm{~s}$

samples simulated with different cooling rates, as shown in Fig. 5. According to the different structural characteristics shown in Fig. 5a, there are two types of island structures. One is larger and flat with white edges, indicated by the black arrows. The other is smaller and white on the whole, indicated by the white arrows. TEM investigations were performed subsequently to clarify the two kinds of island structures. As shown in Fig. 5b, the large island structures are composed of the bainite in the center and M-A constituents on the edge. And as shown in the Fig. 5c, the small island structures are irregularly block-shaped M-A constituents which distribute at the grain boundaries. According to the study of Shang et al. [17], the diffusivity is enough for carbon to diffuse from grain center to grain boundaries during the process of intercritical heating. Then during the process of cooling, the bainite nucleated and grew into supercooled austenite and the bainite/austenite interfaces moved toward austenite, leading to the increase in carbon content in remaining austenite. As temperature further decreased, the carbon-rich austenite transformed into M-A constituents finally. Carbon concentration is necessary for the formation of M-A constituents because carbon enrichment can increase the stability of residual austenite notably and decrease the martensite start temperature at these local zones [18]. According to the further amplification micrograph of M-A constituents, it can be found that the substructure of the martensite in $\mathrm{M}-\mathrm{A}$ constituents is twin (Fig. 5d). It is generally accepted that the twin structure is obtained in the HAZ not only because of the high cooling rate but also the inhomogeneity of carbon concentration inside the austenite and the thermal stresses in the HAZ. Recent study also reported that the formation of the twin martensite can relieve the stress induced by high temperature, solidification and phase transformation [19].

The area fraction of $\mathrm{M}-\mathrm{A}$ constituents and reverted austenite at intercritical temperature were estimated according to the different gray levels between M-A constituents and bainite and ferrite by using image processing software Image Pro, and the results are illustrated in Fig. 6. On the basis of the analysis above, the area fraction of reverted austenite at intercritical temperature is equal to the 

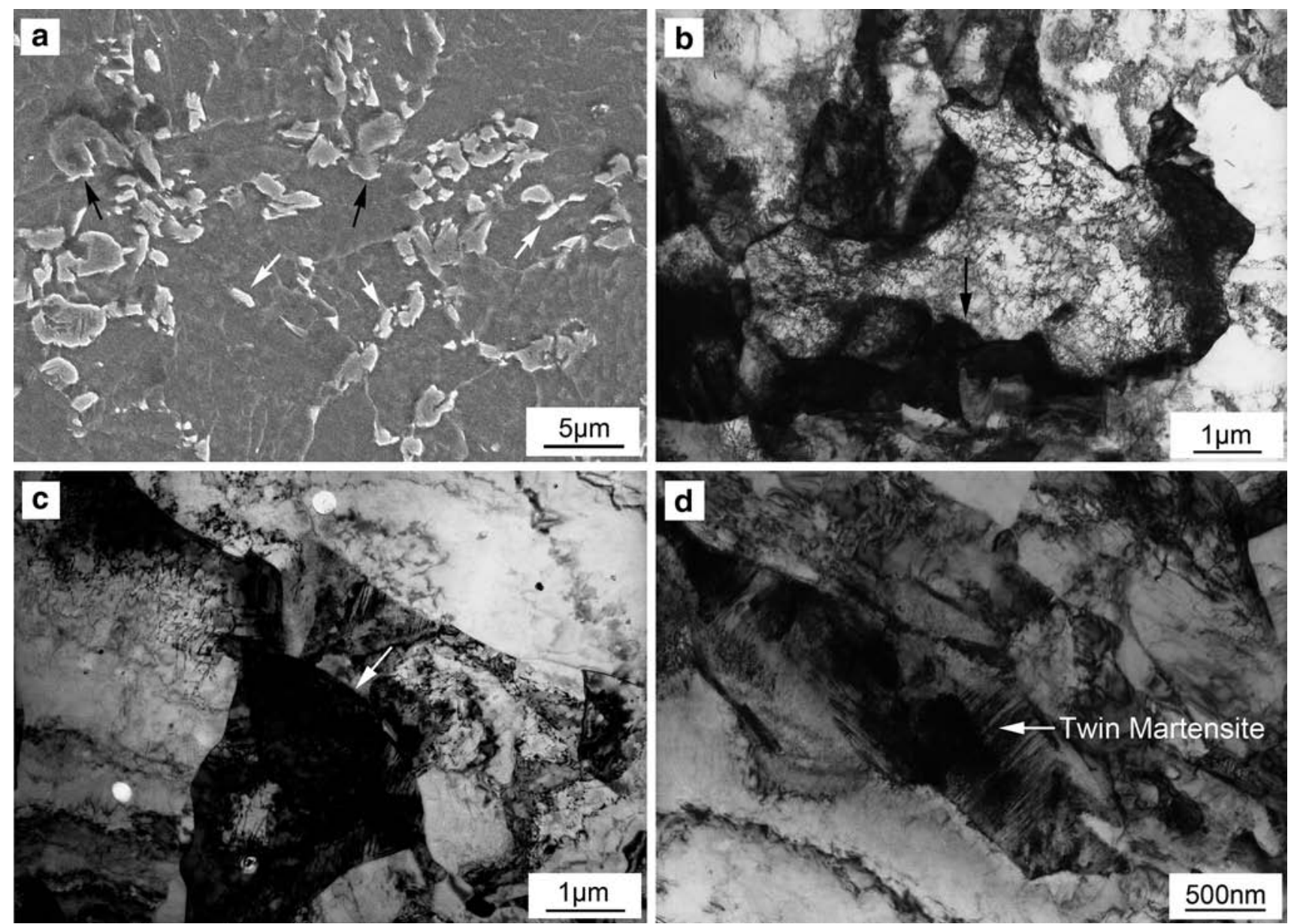

Fig. 5 Microstructure of ICHAZ simulated with different cooling rates: a SEM micrograph when $t_{8 / 5}=2.5 \mathrm{~s}$; b TEM micrograph of stringer shape M-A constituents when $t_{8 / 5}=4.0 \mathrm{~s}$; c TEM micrograph of block-shaped M-A constituents when $t_{8 / 5}=5.5 \mathrm{~s} ; \mathbf{d}$ TEM micrograph of martensite when $t_{8 / 5}=5.5 \mathrm{~s}$

sum of the area fraction of M-A constituents and fine bainite and ferrite, which can be estimated if their sizes are smaller than the threshold value. The result shown in Fig. 6 is corresponding to the research results $[20,21]$ that for low-carbon microalloyed steel, the area fraction of reverted austenite at intercritical temperature is more than $20 \%$ when heating to $800{ }^{\circ} \mathrm{C}$ continuously, regardless of cooling process. With the decrease in the cooling rate, the area fraction of M-A constituents increased from 10.5 to $11.9 \%$ firstly (Fig. 6). However, the area fraction of M-A constituents fell to $8.5 \%$ when $t_{8 / 5}$ is $15 \mathrm{~s}$, although the fraction of reverted austenite at intercritical temperature increased continuously. According to Biss's research [22], the diffusion of $\mathrm{C}$ atoms in carbon-rich austenite is suppressed during the process of rapid cooling, resulting in a small area fraction of M-A constituents. And with the decrease in the cooling rate, the area fraction of reverted austenite at intercritical temperature increases and the long-range diffusing ability of $\mathrm{C}$ atoms grows. Although the maximum concentration of $\mathrm{C}$ atoms inside the reverted austenite

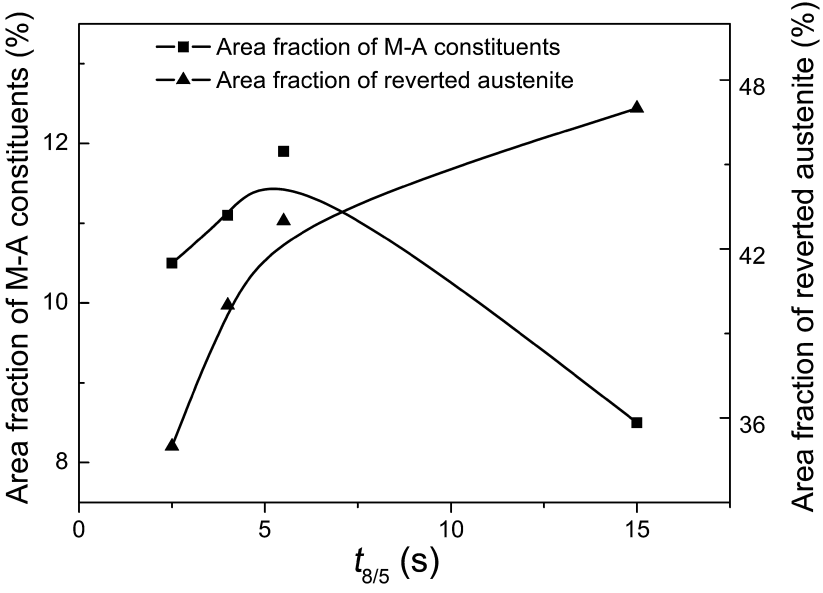

Fig. 6 Area fractions of $\mathrm{M}-\mathrm{A}$ constituents and reverted austenite at intercritical temperature of ICHAZ with different cooling rates

reduces, the areas that meet the condition of the martensite phase transformation increase. These additional areas of carbon-rich residual austenite will transform into M-A 
constituents during cooling process. As further decrease in the cooling rate, the reverted austenite tends to decompose into ferrite and bainite instead of martensite, which has an effect on inhibiting the formation of $\mathrm{M}-\mathrm{A}$ constituents.

\subsection{Second Phase Particles}

Besides, some second phase particles with large size were observed by TEM, as shown in Fig. 7. According to EDS analysis (Fig. 7b, d), the main components of these particles were $\mathrm{Ti}, \mathrm{Nb}, \mathrm{C}, \mathrm{Cu}$ and $\mathrm{Fe}$. Those second phase particles which have high melting point did not melt due to the relatively low simulate peak heating temperature of ICHAZ but coarsened in the process of heating and cooling. Recent study showed that at a certain temperature, the area fraction of carbides is invariable [23]. So with the carbides coarsening, some fine carbides dissolved. As a result, the pinning effect of the precipitates reduced. As measured by using the linear intercept method, the average grain size of untransformed bainite and ferrite is 15.2, 17.5,
20.2 and $25.3 \mu \mathrm{m}$ when $t_{8 / 5}$ is $2.5,4,5.5$ and $15 \mathrm{~s}$, respectively.

\subsection{Hardness and Charpy Impact Testings}

The Vickers hardness of ICHAZ with different cooling rates was investigated, and the result is shown in Fig. 8. According to the result, the Vickers hardness increased with the raise of the cooling rate which can be explained as the reduction in grain size and the increment in defects density. Because hardness is an important indicator for evaluating cold cracking sensitivity, the result shown in Fig. 8 indicates that the susceptibility to cold cracking is relatively high for rapid cooling. It is also worth noting that the variation trend of the Vickers hardness is not in accordance with the area fraction of M-A constituents for ICHAZ (Fig. 6). That is to say the area fraction of M-A constituents has little effect on the Vickers hardness. It may be due to a few difference of the area fraction of $\mathrm{M}-\mathrm{A}$ constituents among the samples simulated with $t_{8 / 5}$ of $2.5,4.0$ and $5.5 \mathrm{~s}$.
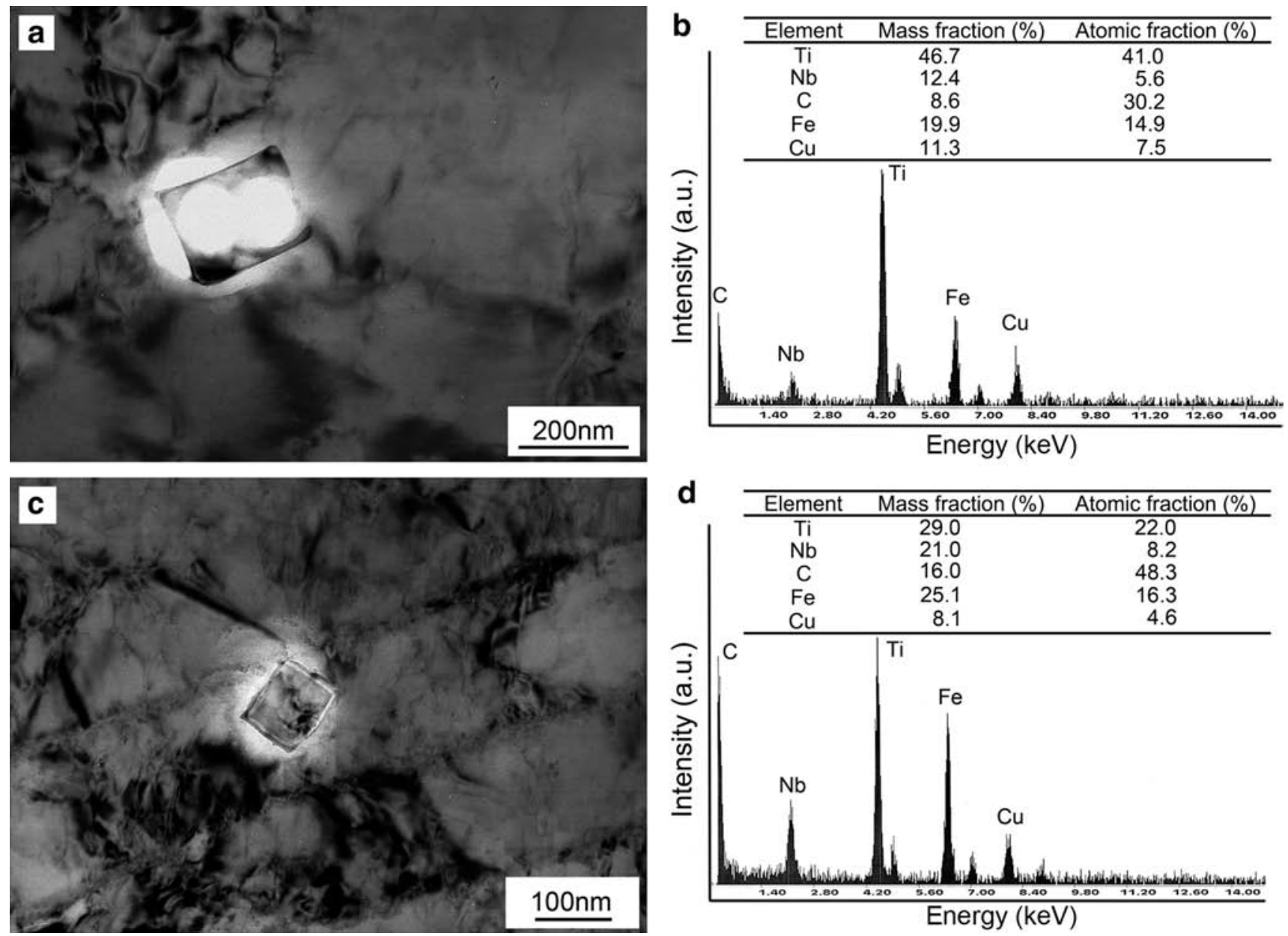

Fig. 7 Second phase particles in ICHAZ: a, c second phase particles; $\mathbf{b}$ EDS analysis result of $\mathbf{a}$; $\mathbf{d}$ spectral analysis result of $\mathbf{c}$ 


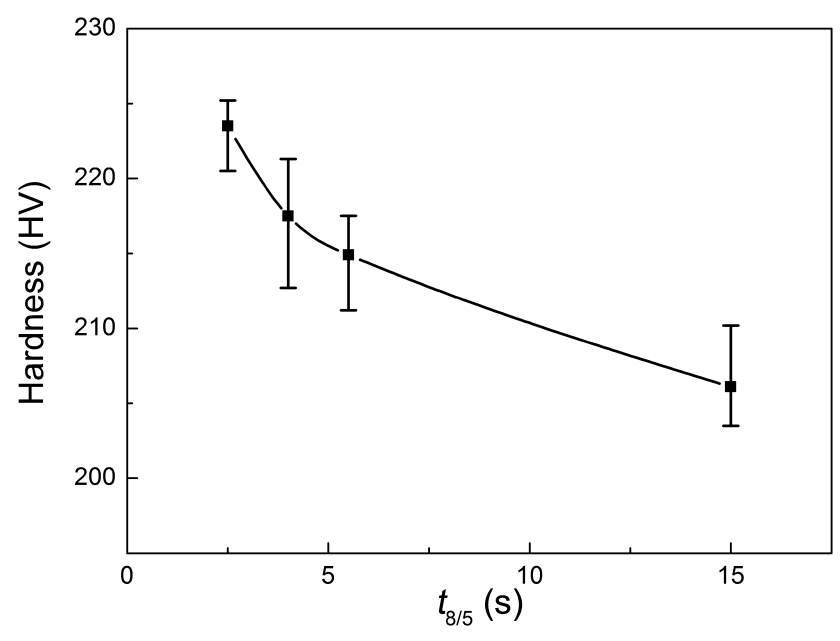

Fig. 8 The Vickers hardness of ICHAZ with different cooling rates

The low-temperature $\left(-20{ }^{\circ} \mathrm{C}\right)$ impact absorbed energy of ICHAZ samples simulated with $t_{8 / 5}$ of 5.5 and $15 \mathrm{~s}$ was investigated, and the result is shown in Fig. 9. Combined with the area fraction of M-A constituents (Fig. 6) and the impact absorbed energy of ICHAZ (Fig. 9), it can be induced that the toughness decreased sharply with the increase in M-A constituents. That is generally because the hard and brittle M-A constituents can hinder dislocation motion and then make the dislocation pile-up during plastic deformation; additionally, M-A constituents also generate stress concentration under applied stress owing to the mismatching of hardness of the matrix and M-A constituents.

Figure 10 shows the SEM morphologies of fractography of ICHAZ samples simulated with different cooling rates. When $t_{8 / 5}$ is $5.5 \mathrm{~s}$, the fracture morphology has recognizable characteristics of river pattern (Fig. 10a) so the

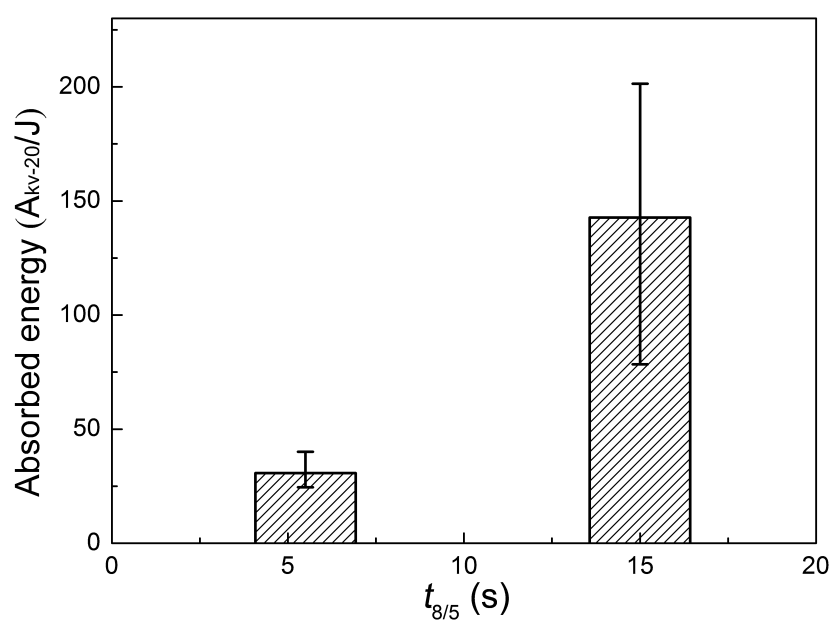

Fig. 9 Low-temperature $\left(-20^{\circ} \mathrm{C}\right)$ impact absorbed energy of ICHAZ with $t_{8 / 5}$ of $5.5 \mathrm{~s}$ and $15 \mathrm{~s}$ fracture mode can be regarded as cleavage fracture. Besides, the size of the cleavage plane is relatively large representing low crack propagation energy. When $t_{8 / 5}$ is $15 \mathrm{~s}$, the fracture morphology shows the dimple feature (Fig. 10b) that represents the ductile fracture mode. It is found that under the same condition including the material, load and external environment, the size of dimple changes linearly with the dimension and the spacing of the second phase particles [24]. When a number of M-A constituents act as nucleation of dimples, the dimples will connect with each other after extending a short distance because of the small spacing, resulting in the small size of the dimples (Fig. 10b).

\subsection{M-A Constituents and Fracture}

The hard and brittle M-A constituents with high stress concentration have much effect on the toughness of ICHAZ. Based on previous studies, Davis and King [25] collated four fracture-initiating mechanisms related to MA constituents. No matter in which mechanism, the existence of M-A constituents will promote the crack initiation greatly. Thus, with the increase in area fraction of $\mathrm{M}-\mathrm{A}$ constituents, cracks initiated easily under external force, resulting in the decrease in toughness. Besides, current research showed the size and distribution of M-A constituents also affect the toughness notably [26]. Based on fracture mechanics, the critical cracking stress of actual metal material at the crack tip can be described as formula (1) $[27]:$

$\sigma_{\mathrm{c}}=\left[\left(2 \gamma+\gamma_{\mathrm{p}} / \pi \mathrm{a}\right) E\right]^{1 / 2}$.

where $\sigma_{\mathrm{c}}$ is the critical cracking stress in the crack tip, $E$ is the Young's modulus of materials, $\gamma$ is the effective surface energy of the crack tip, $\gamma_{\mathrm{p}}$ is the plastic deformation energy which is much larger than $\gamma$ and is the main resistance of crack propagation in metal materials, $a$ is the size of microcrack which serves as the size of M-A constituents in this study. From the formula (1), $\sigma_{\mathrm{c}}$ decreases continuously with the increase in the size of $\mathrm{M}-\mathrm{A}$ constituents, causing the toughness deteriorated sharply. And Li and Baker also suggested that large blocky M-A constituents have a preference for debonding from the matrix during deformation [28]. Additionally, many studies showed that when $\mathrm{M}-\mathrm{A}$ constituents distribute at the grain boundaries and connect as chains shape, the toughness deteriorates rapidly $[25,29]$. Mohseni et al. [30] reported that when the space between blocky $\mathrm{M}-\mathrm{A}$ constituents is close, the stress concentration will be enlarged because the transformation induced stress fields overlap.

Under in-service welding condition when $t_{8 / 5}$ is $5.5 \mathrm{~s}$, the area fraction and size of $\mathrm{M}-\mathrm{A}$ constituents were large. 

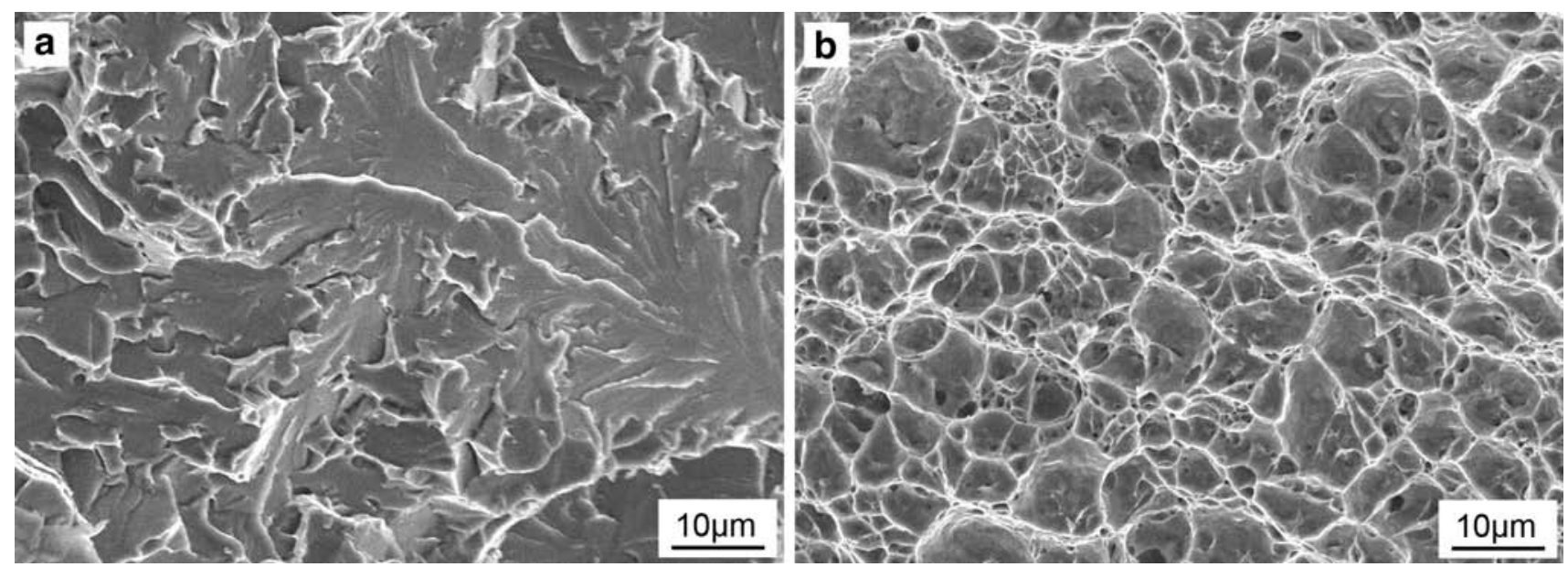

Fig. 10 SEM fractographs of Charpy impact test: a $t_{8 / 5}=5.5 \mathrm{~s} ; \mathbf{b} t_{8 / 5}=15 \mathrm{~s}$

They often connected together into chains and distributed at the grain boundaries. So as stated above, the toughness of ICHAZ with $t_{8 / 5}$ of $5.5 \mathrm{~s}$ is particularly poor, as shown in Fig. 9. Under normal welding condition when $t_{8 / 5}$ is $15 \mathrm{~s}$, both the area fraction and size of M-A constituents reduced due to the relatively low cooling rate. Additionally, the M-A constituents is dispersed and no longer connected into chains. As a result, toughness of ICHAZ under normal welding condition increased more than that under in-service welding condition.

\section{Conclusions}

(1) Under the condition of in-service welding process, the microstructure of ICHAZ consisted of the bainite, ferrite and $\mathrm{M}-\mathrm{A}$ constituents.

(2) As the decrease in the cooling rate, the content of MA constituents increased firstly and then decreased, and the $(\mathrm{Ti}, \mathrm{Nb}) \mathrm{C}$ particles coarsened during heating and cooling.

(3) The Vickers hardness of ICHAZ decreased with the decrease in the cooling rate which is independent with the area fraction of $\mathrm{M}-\mathrm{A}$ constituents.

(4) In the condition of in-service welding, the large area fraction and size of M-A constituents that connected into chains and distributed at the grain boundaries led to a considerable reduction in toughness. As the cooling rate was low relative in the normal welding condition, the toughness increased because of the decrease in the area fraction and the size of M-A of $\mathrm{M}-\mathrm{A}$ constituents.

Acknowledgments This research was financially supported by Key Project of Tianjin Municipal Science and Technology Support
Program (No. 11ZCGYSF00100), and Tianjin Natural Science Foundation (No. 11JCYBJC06000), and the Gansu province Science and Technology Support Program (No. 1204GKCA007).

\section{References}

[1] Z.Y. Huang, Q. Shi, F.Q. Chen, Y.F. Shi, Acta Metall. Sin. (Engl. Lett.) 27, 421 (2014)

[2] A. Lambert-Perlade, A.F. Gourgues, J. Besson, T. Sturel, A. Pineau, Metall. Mater. Trans. A 35, 1053 (2004)

[3] L.Y. Lan, C.L. Qiu, D.W. Zhao, X.H. Gao, L.X. Du, Mater. Sci. Eng. A 529, 200 (2011)

[4] Y. You, C.J. Shang, N. Wenjin, S. Subramanian, Mater. Sci. Eng. A 558, 701 (2012)

[5] L.Y. Lan, C.L. Qiu, D.W. Zhao, X.H. Gao, L.X. Du, Acta Metall. Sin. 47, 1054 (2011). (in Chinese)

[6] M.A. Wahab, P.N. Sabapathy, M.J. Painter, J. Mater. Process. Technol. 168, 422 (2005)

[7] X.L. Xue, J.G. Zhu, G.E.O. Widera, Z.F. Sang, J. Press. Vessel Technol. 129, 72 (2005)

[8] C.W. Li, Y. Wang, Mater. Des. 52, 1057 (2013)

[9] V.T. Farid, M.A. Hamed, J. Appl. Sci. 9, 626 (2009)

[10] P.T. Jia, T. Han, Y. Wang, Trans. China Weld. Inst. 34, 37 (2013). (in Chinese)

[11] H.M. Asl, A. Vatani, Int. J. Press. Vesssel Pip. 105-106, 59 (2013)

[12] C.W. Li, Y. Wang, T. Han, B. Han, L.Y. Li, J. Mater. Sci. 46, 733 (2011)

[13] Y. Wang, L.J. Wang, X.J. Di, Y.T. Shi, X.W. Bao, X.M. Gao, Comput. Mater. Sci. 68, 205 (2013)

[14] K.W. Andrews, J. Iron Steel Inst. 203, 727 (1965)

[15] Z.C. Liu, H.P. Ren, Austenite Formation and Pearlite Transformation, 1st edn. (Metallurgical Industry Press, Beijing, 2010), p. 32. (in Chinese)

[16] Y. You, C.J. Shang, L. Chen, S. Subramanian, Mater. Des. 43, 491 (2013)

[17] X.D. Li, X.P. Ma, S.V. Subramanian, C.J. Shang, R.D.K. Misra, Mater. Sci. Eng. A 616, 147 (2014)

[18] L.Y. Lan, C.L. Qiu, D.W. Zhao, X.H. Gao, L.X. Du, J. Mater. Sci. 47, 4742 (2012)

[19] K. Poorhaydari, B.M. Patchett, D.G. Ivey, Mater. Sci. Eng. A 435-436, 382 (2006) 
[20] M. Chang, H. Yu, Int. J. Min. Metall. Mater. 20, 432 (2013)

[21] J. Huang, W.J. Poole, M. Militzer, Mater. Trans. A 35, 3375 (2004)

[22] V. Biss, R.L. Cryderman, Metall. Trans. 2, 2267 (1971)

[23] L.M. Fu, H.R. Wang, W. Wang, A.D. Shan, Mater. Sci. Technol. 27, 1001 (2011)

[24] Q.P. Zhong, Z.H. Zhao, Fractography, 1st edn. (Higher Education Press, Beijing, 2006), pp. 153-156. (in Chinese)

[25] C.L. Davis, J.E. King, Metall. Mater. Trans. A 25, 573 (1994)
[26] X.D. Li, X.P. Ma, S.V. Subramanian, C.J. Shang, R.D.K. Misra, Metall. Mater. Trans. E (in press)

[27] G.R. Irwin, Fracture Dynamics: Fracture of Metals (America Society for Metals, Cleveland, 1948), pp. 147-166

[28] Y. Li, T.N. Baker, J. Mater. Sci. Technol. 26, 1040 (2010)

[29] X.D. Li, Y.R. Fan, X.P. Ma, S.V. Subramanian, C.J. Shang, Mater. Des. 67, 457 (2015)

[30] P. Mohseni, J.K. Solberg, M. Karlsen, O.M. Akselsen, E. Østby, Metall. Mater. Trans. A 45, 394 (2014) 